\title{
Study of Rock Blasting Failure Pattern with One Free Boundary
}

\author{
Jun Yang, ${ }^{1}$ Xin Liu $\mathbb{D},{ }^{1}$ Zhenyang Xu, ${ }^{2}$ Hongliang Tang, ${ }^{1}$ and Qi Yu ${ }^{3}$ \\ ${ }^{1}$ State Key Laboratory of Explosion Science and Technology, Beijing Institute of Technology, Beijing 100081, China \\ ${ }^{2}$ School of Mining Engineering, University of Science and Technology Liaoning, Anshan 114051, Liaoning, China \\ ${ }^{3}$ China Ordnance Industry Fire and Explosives Engineering and Safety Technology Research Institute, \\ China North Industries Group Corporation Limited, Beijing 100053, China
}

Correspondence should be addressed to Xin Liu; xinliu0412@foxmail.com

Received 6 February 2020; Revised 25 July 2020; Accepted 19 August 2020; Published 28 August 2020

Academic Editor: Chunshun Zhang

Copyright (c) 2020 Jun Yang et al. This is an open access article distributed under the Creative Commons Attribution License, which permits unrestricted use, distribution, and reproduction in any medium, provided the original work is properly cited.

\begin{abstract}
The study of rock blasting failure pattern is of engineering importance. In order to investigate rock blasting failure pattern with one free boundary, high-speed photography technology is introduced into the two-dimensional granite model. Through highspeed camera images, a crack that originated from spalling is observed and then propagates inward. By using the high-speed digital image correlation method, the full-strain fields on the surface of the specimens are calculated. The preliminary results show that von Mises strain localization appears on the specimen surface near the free boundary. The axial strains near that crack present three kinds of characteristics. There are the joint action areas of the strain localization by analyzing strains in different directions, and the strain localizations are related to the crack propagation. Ultimately, after analysis of the experimental results, the preliminary diagrammatic drawing of rock blasting failure pattern under stress wave action with one free boundary is drawn.
\end{abstract}

\section{Introduction}

The study of fracture initiation and propagation in rock blasting is of engineering importance. For a long time, researchers and field technicians in mining engineering, civil engineering, petroleum engineering, and other rock blasting fields have constantly improved the rock breakage mechanism. In general, rock breakage mechanism is attributed to one or more of the following factors: tensile reflected waves, compressional stress waves, gas pressure, flexural rupture, and nuclei stress flaw. For better understanding of phenomena governing dynamic fracture initiation and propagation, Saharan et al. [1] proposed that a systems engineering approach is required. And they presented a detailed review of the role of various systems and subsystems on dynamic rock fracture initiation and propagation.

Various experimental methods and laboratory-scale specimens have been employed to investigate the subsystem of free face effect on dynamic fracture initiation and propagation. Using three-dimensional Perspex models, Field and Ladegaard-Pedersen [2] argued that the reflected stress waves are of prime instrumental in assisting development of the cracks and determining direction of the fractures at a critical stage. From experimental and theoretical results on two-dimensional Plexiglas, Kutter and Fairhurst [3] concluded that a free boundary normally prefers the generation and extension of radial cracks when they propagate towards the surface. Via application of holographic interferometry on two- and three-dimensional specimens, Holloway [4] obtained clear photographs of radial cracks which emanate from the borehole region, and a radially orientated crack initiates at the free boundary and thus propagates inwards. Wilson and Holloway [5] performed laboratory-scale bench blasting experiments using concrete blocks; they found that fractures important to the final fragmentation are initiated in the free surfaces nearest to the charge by the reflecting $P$-wave. In addition, in order to examine the use of stress waves and fracture mechanics in understanding dynamic fracture and fragmentation in blasting applications, Fourney [6] presented a review on the work conducted in the past at the Dynamic Effects Laboratory.

Although many short cracks grow from near the borehole due to explosive energy, the number of 
dominant radial cracks decreases after a short distance. From experimental results, Persson et al. [7] concluded that the number of prominent cracks is about six. Field and Ladegaard-Pedersen [2] stated that the number of symmetrically positioned cracks is usually between four and eight. Langefors and Kihlstrom [8] found that the number of prominent cracks is between eight and twelve; Fourney [6] has confirmed the number in their experiments.

Recently, the strain localization and evolution are popular to investigate the dynamic responses of rocks in SHPB test with digital image correlation (DIC) [9-11]. On top of this application, DIC has been employed to measure in full-field deformation information on blasting experiments with rock, polycarbonate, and polymethyl methacrylate (PMMA). For example, Yang et al. [12] investigated the combined action of the blast-induced stress wave in decoupled charge blasting. Yang et al. [13] studied strain evolution process of blasting under high stress condition. Yang et al. [14] studied the effects of the filling medium and the decoupling coefficient on stress evolution in decoupled charge blasting. Chi et al. [15] studied full-field strain variation with different charge weights. He et al. [16] observed blast loading response process and the dynamic strain under different confining pressures. Moreover, Sutton et al. [17] presented a detailed review and discussion of using digital image correlation.

As is well known, DIC carried out correlation calculation by the matrix of the gray values in speckle images before and after specimen deformation, and the spatial position of the calculated point before and after specimen deformation is tracked; then the displacement and strain information of the specimen surface is obtained. Therefore, to solve the correspondence investigation uniquely, the specimen surface has to exhibit certain properties, that is, speckle pattern should, therefore, be nonperiodic [17]. From the existing literature records, on the one hand, Yang et al. [12] used an ultraviolet plate-printing technique to place speckles $1.2 \mathrm{~mm}$ in diameter with a $75 \%$ density and a $75 \%$ irregularity on the specimen surface. On the other hand, Chi et al. [15] and He et al. [16] used the texture of the granite itself as speckle pattern.

From the existing research, the study of rock blasting of two-dimensional specimens with one free boundary based on DIC is rarely studied. In this paper, we particularly focus on the functional mechanism of rock blasting failure pattern with one free boundary; the fullfield strain evolution of blasting stress wave action is analyzed by two-dimensional granite model experiments with experimental system of high-speed digital image correlation. And the generation and propagation of cracks are also obtained.

\section{Granite and Experiment Method}

2.1. Specimen Parameters. Wulian Flower Granite (G3761) is selected from Shandong province for this study. Polarizing microscope images (LEICA DM2500 p), which is tested by the parameter of $10 \times 2.5$ (eyepiece multiple $\times$ objective multiple), are obtained from Yunenng geological service (Langfang, China), as shown in Figure 1 and Table 1. Based on the International Society for Rock Mechanics (ISRM) standards, cylindrical specimens for uniaxial static compressive strength tests $(50 \times 100 \mathrm{~mm})$ and static tensile strength tests $(50 \times 25 \mathrm{~mm})$ are cored from the same rock block without obvious joint surface, and five replicate tests are performed for each property by using the hydraulic screen-display universal testing machine (WEP-600). The specimens are homogeneous with the following average values: density $\rho=2578 \mathrm{~kg} / \mathrm{m}^{3}, P$-wave velocity $V_{p}=4386 \mathrm{~m} /$ s, elastic modulus $E=35.43 \mathrm{GPa}$, Poisson's ratio $\nu=0.15$, uniaxial static compressive strength $\sigma_{c}=70.65 \mathrm{MPa}$, and static tensile strength $\sigma_{t}=3.26 \mathrm{MPa}$.

2.2. Experimental System. As shown in Figure 2, the granite specimen is a $500 \mathrm{~mm}$ length, a $500 \mathrm{~mm}$ width, and a $20 \mathrm{~mm}$ thickness, and the borehole is drilled with a $120 \mathrm{~mm}$ distance from the free boundary. And the borehole diameter varied as $\Phi_{B}=10,12,14$, and $16 \mathrm{~mm}$. Test 1 to test 4 are defined in the order of the borehole diameter from small to large; that is, the borehole diameter of $10 \mathrm{~mm}$ is corresponding to test 1 . The 8\# detonator is used in this study and taped tightly until it fit the borehole. A self-designed holder with a clamp is used to fix the test specimen and reduce the effects of blasting gas on the shooting picture. In addition, we only study the blasting stress wave effect.

The experimental high-speed DIC system shown in Figure 2 is set up in the State Key Laboratory of Explosion Science and Technology at the Beijing Institute of Technology (Beijing) and is selected for blasting experiments. As shown in Figure 2, the main components of this experimental system are high-speed camera (Photron Fastcam SA5), MatchID software, lighting system (Godox SL$200 \mathrm{~W}$ ), and synchronous trigger system. And the resolution is set as 256 pixels $\times 176$ pixels at a frame rate of $100,000 \mathrm{fps}$. Parameter setting of MatchID software involves the following contents: subset is 21 pixels, step size is 3 pixels, correlation criterion is zero-normalized sum of squared differences (ZNSSD), and shape function is affine. Other parameters are set as the default parameters of MatchID software.

\section{Results and Discussion}

Figure 3 shows the high-speed camera frames of the evolution of visible cracks. It can be seen that dominant horizontal cracks formed by $100 \mu$ s and those cracks are known as spalling. There is a crack that originated from spalling and propagated inward by $250 \mu \mathrm{s}$. When an explosive detonates under a surface, blasting causes two types of waves-a $P$ wave and an $S$-wave. When the waves reach a free surface, four waves are caused [18]: (1) a reflected $P$-wave ( $P P$-wave) due to the incident $P$-wave; (2) a reflected $S$-wave ( $S P$-wave) due to the incident $P$-wave; (3) a reflected $P$-wave ( $P S$-wave) due to the incident $S$-wave; (4) a reflected $S$-wave (SS-wave) due to the incident $S$-wave. According to the study of Fourney et al. [19], when the reflection process has been 


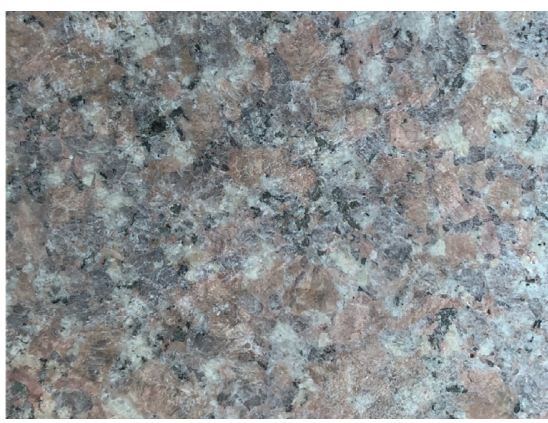

(a)

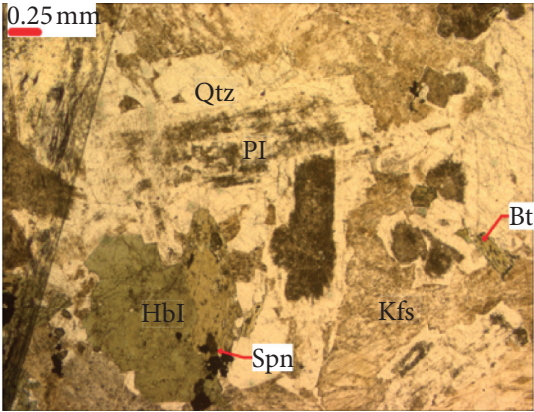

(b)

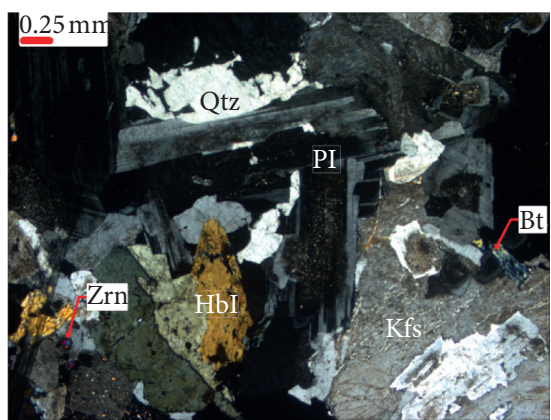

(c)

Figure 1: Sample and polarizing microscope images. (a) The sample surface, (b) plane-polarized light, and (c) cross-polarized light.

TABLE 1: Mineral features according to polarizing microscope images.

Minerals

Potassium feldspar

(Kfs)

Plagioclase $(\mathrm{Pl})$

Quartz (Qtz)

Biotite (Bt)

Amphibole ( $\mathrm{Hbl})$

Others

\section{Features}

It is semi-idiomorphic, columnar, and argillaceous; it mainly consists of a strip of orthoclase and a stripe of feldspar; and it has a two-long structure with potassium feldspar.

It is semi-idiomorphic, columnar, and polycrystalline and undergo sericitization and zoisite fossilization; it has a two-long structure with plagioclase.

It is xenomorphic-granular. The main grain size is $2-5 \mathrm{~mm}$; some grain size is $0.5-2 \mathrm{~mm}$, and the content is about $20 \%$.

It is idiomorphic schistose, brown, chloritization in varying degrees; it shows metasomatic residual or pseudomorphic structure. The main grain size is $0.2-2 \mathrm{~mm}$, and the content is about $7 \%$.

It is semi-idiomorphic and columnar. The main grain size is $0.5-2 \mathrm{~mm}$, and the content is about $2 \%$.

The auxiliary minerals are magnetite, zircon (Zrn), and apatite (Spn). The altered minerals are sericite, tetrahedrite, and chlorite.

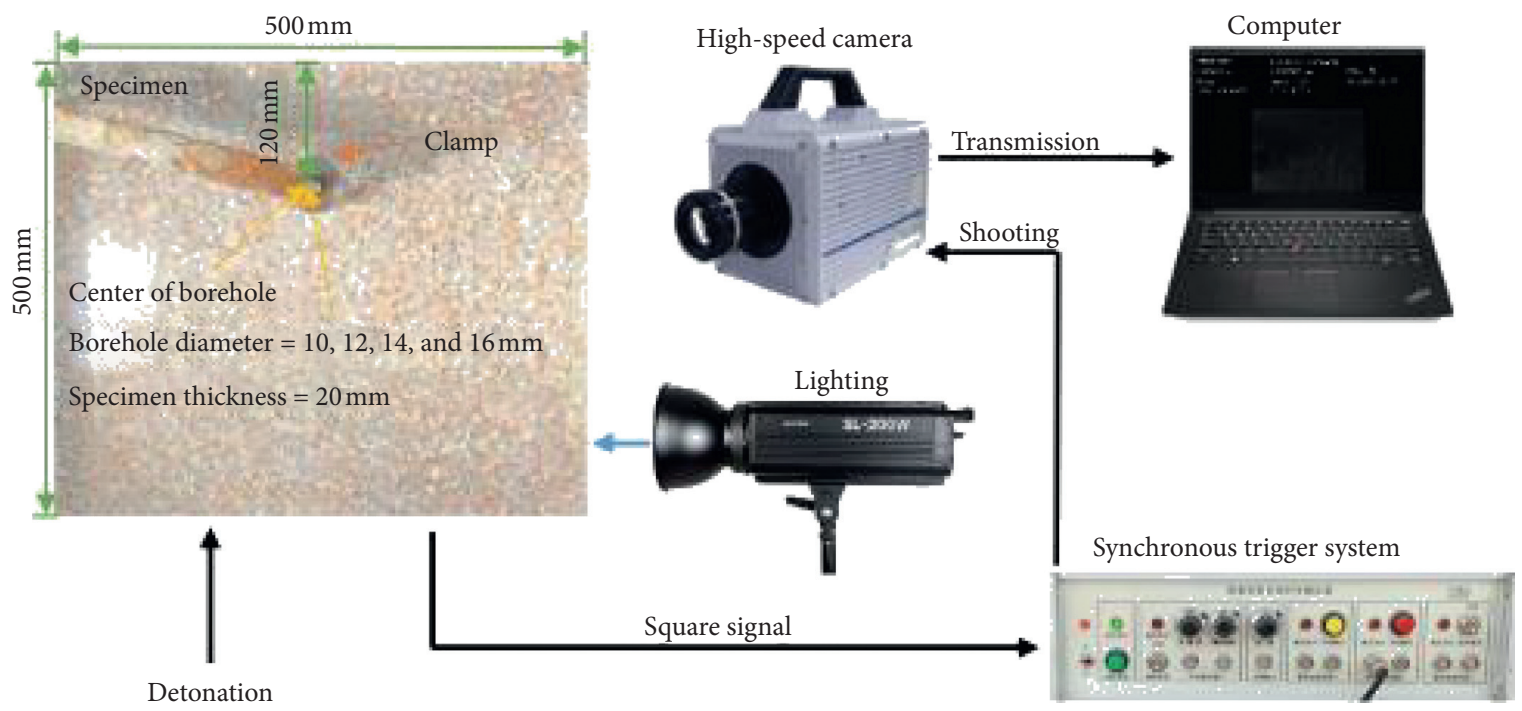

FIGURE 2: Experimental system of the high-speed digital image correlation.

generated at the free boundary, an internal fracture in the form of an I-shaped pattern has formed near the free boundary. After that, a large horizontal crack has propagated from the end points on the I-shaped pattern by the reflected $P P$-wave. When the reflected $P P$-wave has travelled through borehole, a crack perpendicular to the free boundary connects with I-shaped pattern crack and extends towards the charge. This crack is driven by the reflected SS-wave. Similarly, Holloway [4] described that the same phenomenon has been found in experiments with rock material, and he deemed that this crack originated from the circumferential tensile stress in the tail of the $P$-wave. 


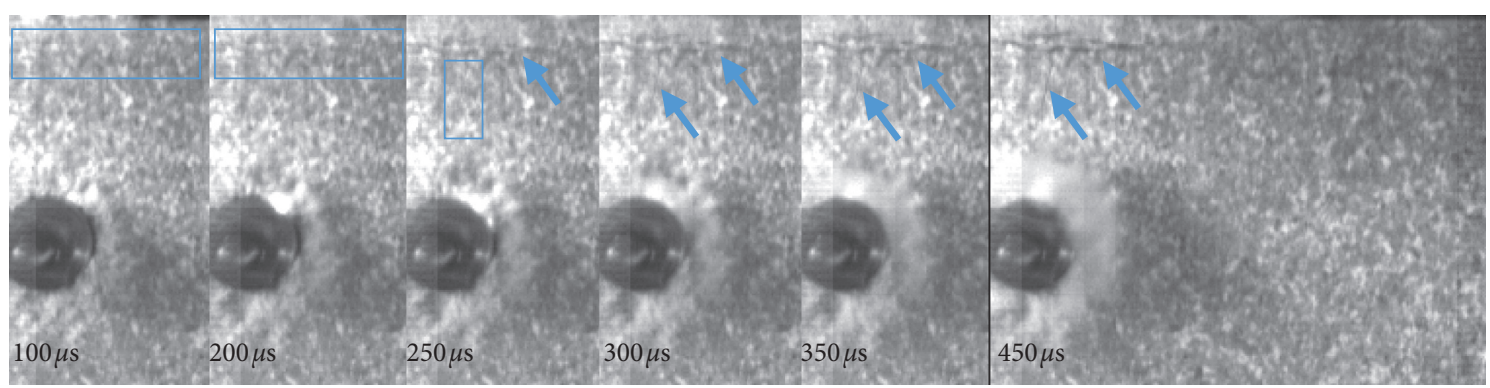

(a)

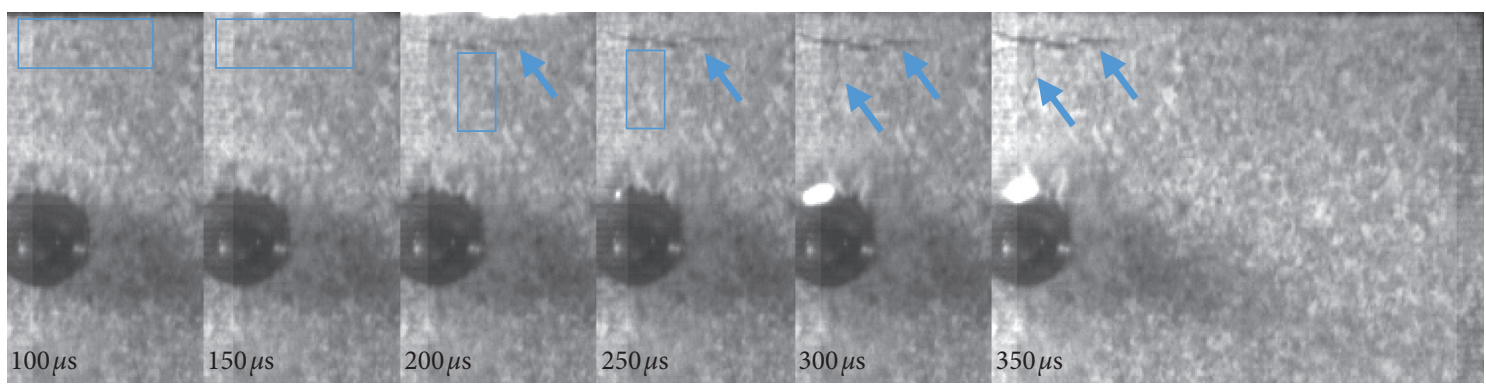

(b)

FIGURE 3: Images of the evolution of visible cracks. (a) Test 2 and (b) test 3.

When the compressive wave travels to the free surface, it is reflected in a tensile wave from the free surface. Note that the stress value of the tensile wave is equal to that of the compressive wave at the free surface. With an increasing time, a large part of the compressive wave is reflected in the tensile wave from the free surface. Both the compressive wave and the tensile wave overlap together between the free surface, resulting in a remained wave [18]. In this paper, the explosive initiation time was $t=0 \mu \mathrm{s}$, and the stress wave propagated to the free boundary at $27.36 \mu$ s for the first time. Von Mises strain field and curves of strain for are shown in Figure 4, ROI (region of interest) was selected approximately at $90 \mathrm{~mm}$ from center of the borehole. Figure 4(a) shows the von Mises strain field at $90 \mu \mathrm{s}$ $\left(\Phi_{B}=12 \mathrm{~mm}\right)$; according to the four tests, the strain localization firstly appeared at $40 \mu \mathrm{s}$; it was formed on the perpendicular line between the borehole and the free boundary and near the free boundary. With an increasing time, it extended horizontally due to reflected wave and the horizontal strain localization emerged gradually from $40 \mu \mathrm{s}$ to $60 \mu \mathrm{s}$. And there are no obvious visible cracks on the specimens from $40 \mu$ s to $90 \mu$ s. Figure 4 (b) shows curves of von Mises strain for ROI data points; thirty images were analyzed by MatchID software and the interval between each image is $10 \mu \mathrm{s}$; that is, the starting point of the data point in Figure 4(b) is $10 \mu \mathrm{s}$, the next point of the data point in Figure 4(b) is $20 \mu \mathrm{s}$, and the end point of the data point in Figure $4(\mathrm{~b})$ is $300 \mu \mathrm{s}$. It can be seen that the relation of the von Mises strain is close to two times between $40 \mu \mathrm{s}$ and $80 \mu \mathrm{s}$, and the role of reflected wave in rock blasting mechanism can also be demonstrated. Meanwhile, we know from Figure 3 that spalling occurred at $100 \mu \mathrm{s}$, and if we choose the Von Mises strain value at $100 \mu$ s as threshold value to estimate the crack propagation, then it can be demonstrated that the spalling occurs earlier than the long radial crack, and the crack that originated from spalling may also occur earlier than the long radial crack.

The strain field in axial $\left(E_{x x}\right)$ direction under the action of blasting stress wave is shown in Figure 5(a). From axial strain fields, strain localization appeared in test 1 , test 2 , and test 3 , and it was formed vertically at the edge of the spalling while there was no sign in test 4 . In order to detect the axial strain near the crack that originated from spalling, six images were analyzed by MatchID software, and Figure 5(b) shows curves of axial strain at different stages for test 2 . The vertical ROI line is away approximately $8 \mathrm{~mm}$ to the $y$-axis, the starting data point $\mathrm{A}$ is $70 \mathrm{~mm}$ in $y$-axis, the interval between data points in ROI line is $3 \mathrm{~mm}$, and the end data point B is $100 \mathrm{~mm}$ in $y$-axis. Meanwhile, the position of measuring point at $94 \mathrm{~mm}$ in $y$-axis is on the crack. It can be seen that the axial strains in every measuring points grow uniformly from $210 \mu$ s to $220 \mu \mathrm{s}$; the axial strains grow unsteadily from $220 \mu \mathrm{s}$ to $250 \mu \mathrm{s}$. Corresponding to Figure 3(a), there is a visible crack by $250 \mu \mathrm{s}$, and there is an abrupt change phenomenon of axial strains from $250 \mu \mathrm{s}$ to $260 \mu \mathrm{s}$ in Figure 5(b). Although the stress wave interaction is complex from $210 \mu \mathrm{s}$ to $260 \mu \mathrm{s}$, the axial strains near crack exhibit certain characteristics.

The strain field in vertical $\left(E_{y y}\right)$ direction under the action of blasting stress wave by $210 \mu \mathrm{s}$ is shown in Figure 6(a). From the vertical strain field, the strain localizations present two regions in test 2 and test 3 . Corresponding to the axial strain field in Figure 5(a), the plots clearly show that the vertical strain localization and the axial strain localization acted together at the coincident positions, which could produce local damage. And it can be seen that 


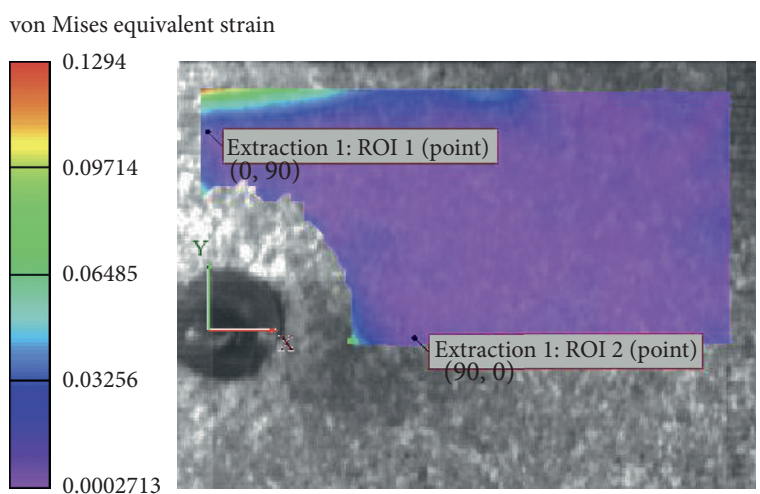

(a)

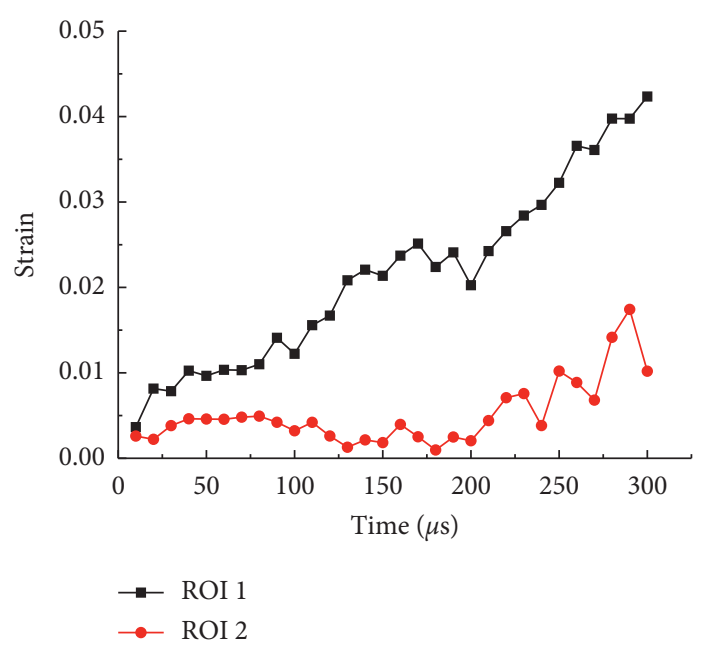

(b)

Figure 4: Von Mises strain for test 2. (a) von Mises strain field at $90 \mu \mathrm{s}$ and (b) curves of von Mises strain.

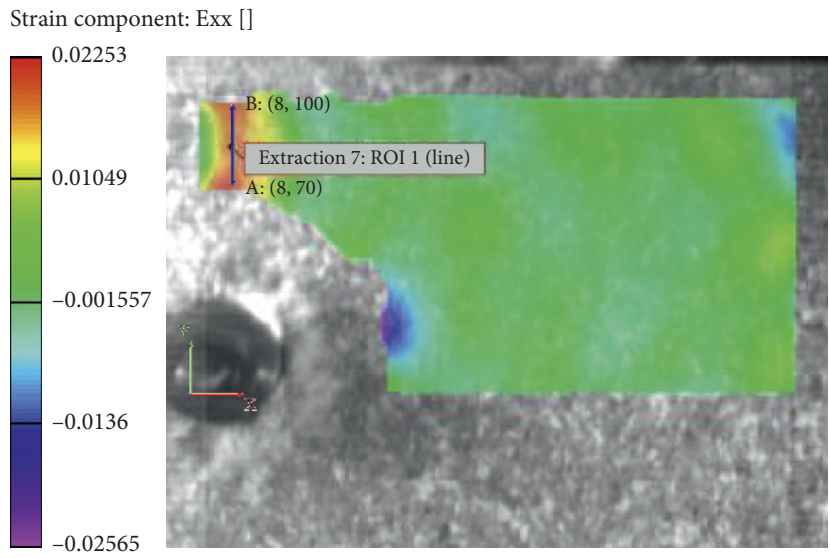

(a)

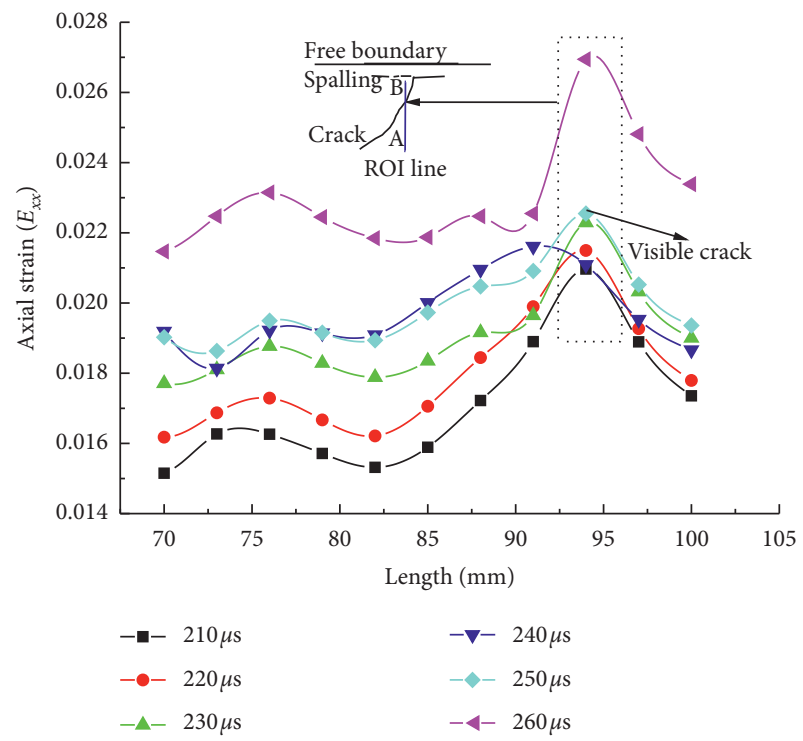

(b)

FIgURe 5: Axial strain for test 2. (a) Axial strain field at $210 \mu$ s and (b) curves of axial strain.

the crack path is basically consistent with the position of strain concentration zone from the axial strain field and the vertical strain field. In addition, it can be confirmed that the crack that originated from spalling is driven by circumferential stress; Figure 6(b) shows diagrammatic drawing of strain field.

Figure 7 shows the specimen failure morphology with different borehole diameters, the position of the ruler scale of $25 \mathrm{~cm}$ is approximately equal to the left and right symmetrical position of the specimen, and the position of the center of the borehole can be estimated. Four long radial cracks (labels A, B, C, and D), two short radial cracks (labels
$\mathrm{H}$ and $\mathrm{I}$ ), and two spalling cracks (labels $\mathrm{E}$ and $\mathrm{F}$ ) are shown in Figure 7(a). Five long radial cracks (labels A, B, C, D, and E) and a spalling crack (label F) are shown in Figure 7(b). Five long radial cracks (labels A, B, C, D, and E) and two spalling cracks (labels $\mathrm{F}$ and $\mathrm{G}$ ) are shown in Figure 7(c). Four long radial cracks (labels A, B, C, and D) and a spalling crack (label E) are shown in Figure 7(d). In the above description, label E in Figures 7(b) and 7(c) is corresponding to the crack that originated from spalling and propagated inward in Figure 3.

According to the failure form and stress characteristics in rock blasting processes, the intense shear stress that 


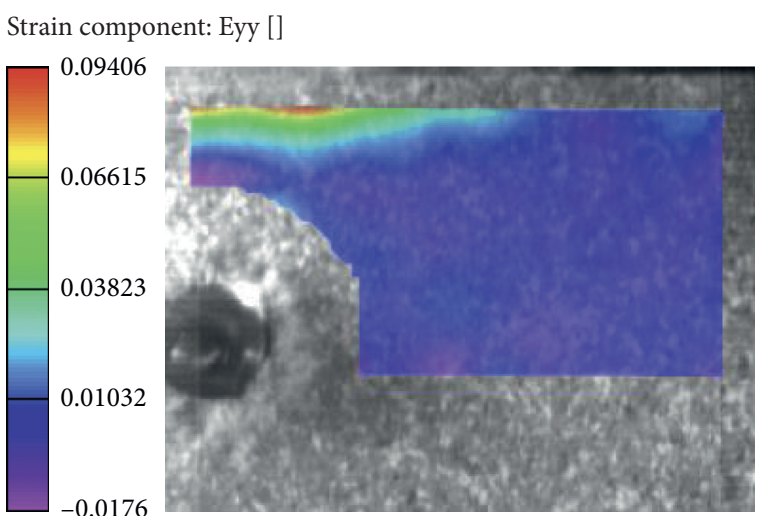

(a)

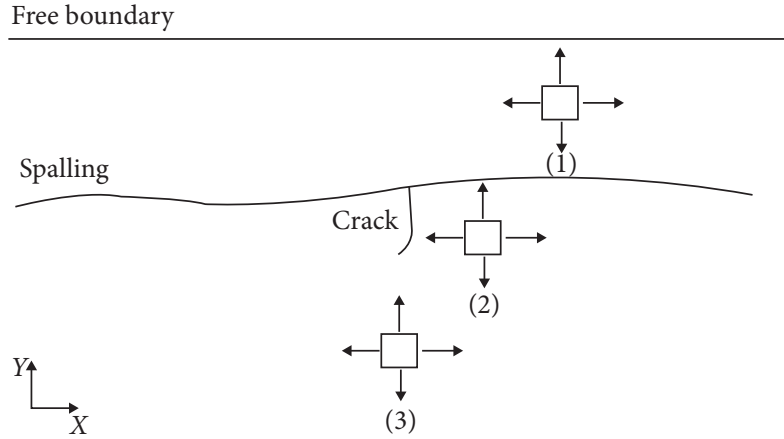

(b)

FIgURe 6: Strain field characteristics. (a) Vertical strain field and (b) diagrammatic drawing of strain field.

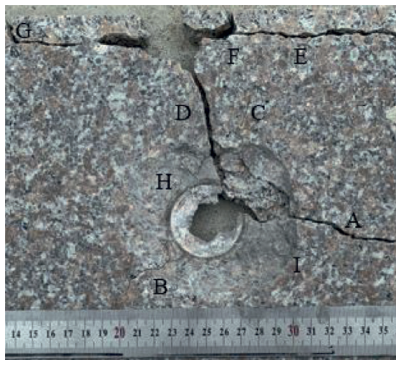

(a)

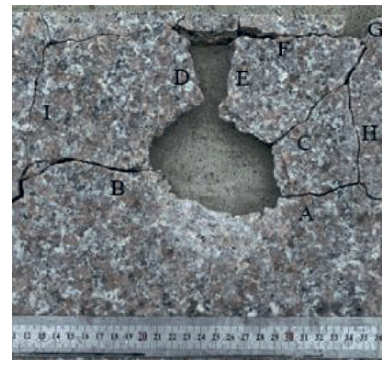

(b)

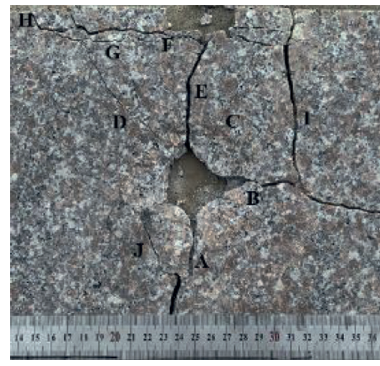

(c)

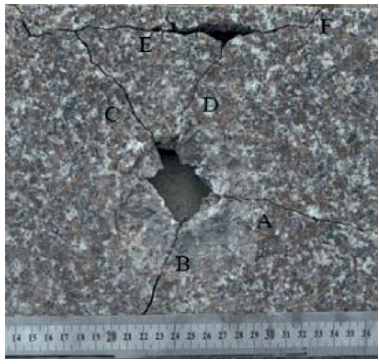

(d)

Figure 7: Specimen failure morphology with different borehole diameters. (a) Test 1, (b) test 2, (c) test 3, and (d) test 4.

came from the $P$-wave causes crushing in the vicinity of the borehole; this compressive leading wave is followed by a tensile tail, which can cause cracking at the borehole wall and this leads to the development of the shear wave [15]. Outside the crushed zone, the tangential tension stress dominates radial crack initiation. When the strain wave reaches the free surface, it is reflected and may cause spalling of surficial slabs. The reflection of the $P$-wave and $S$-wave components drastically influences the propagation behavior of the borehole radial cracks as well as initiating cracks at various flaw sites between the free surface and the borehole [6]. With the introduction of the free boundary, the dynamic fracture process generated by the stress wave at the expansion center becomes more complicated. The fracture process can be divided into twelve different stages according to the time sequence [19]. Analysis of our experimental results after the reflection process shows, first, the spalling occurs; then, the crack initiates from the spalling and begins to grow inward; and, finally, the radial crack originated from the borehole boundary extends to the free boundary. In addition, the diameter of clamp was $50 \mathrm{~mm}$ and few gases leaked from rock and clamp boundary; these factors affect observation of the radial crack propagation; in other words, when the spalling and the crack initiated from the spalling occurred, the radial cracks may not have propagated to $25 \mathrm{~mm}$ or more away from the borehole center. According to our experimental results, diagrammatic drawing of rock blasting failure pattern under stress wave action with one free boundary is shown in Figure 8.

\section{Conclusions}

By using high-speed camera recording two-dimensional granite model under basting stress wave loading and with full-field strain evolution calculated by DIC method to study rock blasting fracture mechanism, the experimental results show the following:

(1) Through observing high-speed camera images, it can be clearly seen that a crack originated from spalling and then propagated inward. Through observing this crack by DIC method, it can be clearly seen that the axial strains present three kinds of characteristics.

(2) There are interaction regions between vertical strain localization and axial strain localization, and this crack is driven by circumferential stress.

(3) According to the final fracture morphology of the samples, the crack distribution state is obtained. Combined with the relevant test data of this test, the number of spalling cracks is one to two, the number of the long radial cracks that originated from the 

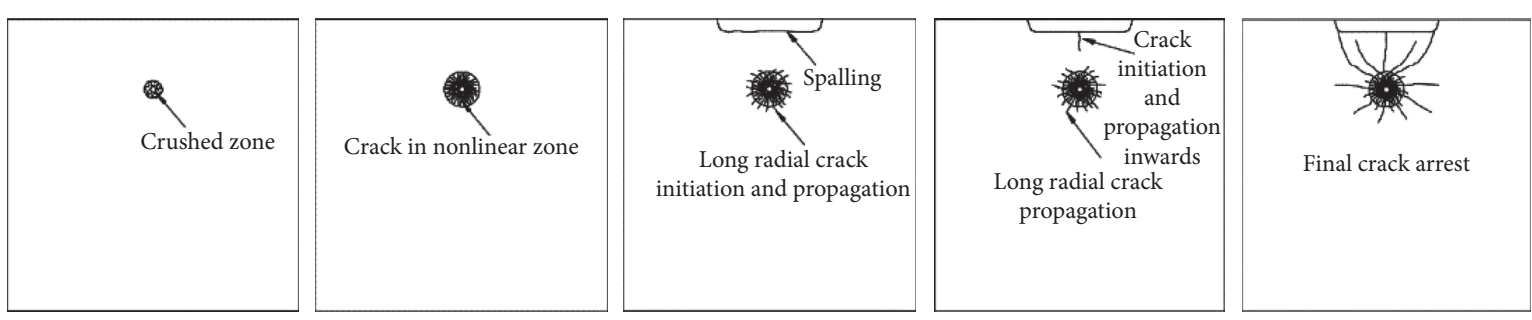

FIgURE 8: Rock blasting failure pattern under stress wave action with one free boundary.

spalling is zero to two, and the number of long radial cracks that originated from the borehole is four to five.

(4) After analysis of the experimental results, the preliminary diagrammatic drawing of rock blasting failure pattern under stress wave action with one free boundary is drawn.

\section{Data Availability}

The data used to support the findings of this study are available from the corresponding author upon request.

\section{Conflicts of Interest}

The authors declare that they have no conflicts of interest.

\section{Acknowledgments}

This research was supported by the National Natural Science Foundation of China (no. 51774043) and Science Foundation Program of Liaoning Province (no. 20170540456).

\section{References}

[1] M. Saharan, H. Mitri, and J. Jethwa, "Rock fracturing by explosive energy: review of state-of-the-art," Fragblast, vol. 10, no. 1-2, pp. 61-81, 2006.

[2] J. E. Field and A. Ladegaard-Pedersen, "The importance of the reflected stress wave in rock blasting," International Journal of Rock Mechanics and Mining Sciences \& Geomechanics Abstracts, vol. 8, no. 3, pp. 213-226, 1971.

[3] H. K. Kutter and C. Fairhurst, "On the fracture process in blasting," International Journal of Rock Mechanics and Mining Sciences \& Geomechanics Abstracts, vol. 8, no. 3, pp. 181-202, 1971.

[4] D. C. Holloway, "Application of holographic interferometry to stress wave and crack propagation problems," Optical Engineering, vol. 21, no. 3, pp. 769-792, 1982.

[5] W. H. Wilson and D. C. Holloway, "Fragmentation studies in instrumented concrete models," in Proceedings of the 6th ISRM congress: International Society for Rock Mechanics, Salzburg, Australia, August 1987.

[6] W. L. Fourney, "The role of stress waves and fracture mechanics in fragmentation," in Proceedings of the 11th International Symposium on Rock Fragmentation by Blasting, pp. 27-39, Sydney, Australia, August 2015.

[7] P. A. Persson, N. Lundborg, and C. H. Johansson, "The basic mechanism in rock blasting," in Proceedings Second Congress of the International Society for Rock Mechanics, Belgrade, Serbia, September 1970.
[8] U. Langefors and B. Kihlstrom, The Modern Technique of Rock Blasting, Wiley, New York, NY, USA, 1963.

[9] Q. B. Zhang and J. Zhao, "Determination of mechanical properties and full-field strain measurements of rock material under dynamic loads," International Journal of Rock Mechanics and Mining Sciences, vol. 60, no. 8, pp. 423-439, 2013.

[10] Q. B. Zhang and J. Zhao, "Effect of loading rate on fracture toughness and failure micromechanisms in marble," Engineering Fracture Mechanics, vol. 102, pp. 288-309, 2013.

[11] H. Z. Xing, Q. B. Zhang, D. Ruan, S. Dehkhoda, G. X. Lu, and J. Zhao, "Full-field measurement and fracture characterisations of rocks under dynamic loads using high-speed threedimensional digital image correlation," International Journal of Impact Engineering, vol. 113, pp. 61-72, 2018.

[12] R. Yang, C. Ding, L. Yang, Z. Lei, Z. Zhang, and Y. Wang, "Visualizing the blast-induced stress wave and blasting gas action effects using digital image correlation," International Journal of Rock Mechanics and Mining Sciences, vol. 112, pp. 47-54, 2018.

[13] L. Y. Yang, C. X. Ding, R. S. Yang, Z. Lei, and J. Wang, "Full field strain analysis of blasting under high stress condition based," Shock and Vibration, vol. 2018, Article ID 4894078, 7 pages, 2018.

[14] R. Yang, C. Ding, L. Yang, Z. Lei, and C. Zheng, "Study of decoupled charge blasting based on high-speed digital image correlation method," Tunnelling and Underground Space Technology, vol. 83, pp. 51-59, 2019.

[15] L. Y. Chi, Z. X. Zhang, A. Aalberg, C. C. Yang, and C. C. Li, "Fracture processes in granite blocks under blast loading," Rock Mechanics and Rock Engineering, vol. 52, no. 3, pp. 853-868, 2019.

[16] C. He, J. Yang, and Q. Yu, "Laboratory study on the dynamic response of rock under blast loading with active confining pressure," International Journal of Rock Mechanics and Mining Sciences, vol. 102, pp. 101-108, 2018.

[17] M. A. Sutton, H. W. Schreier, and J. J. Orteu, Image Correlation for Shape, Motion and Deformation Measurements: Basic Concepts, Theory and Applications, Springer, Berlin, Germany, 2009.

[18] Z. X. Zhang, Rock Fracture and Blasting: Theory and Applications, Butterworth-Heinemann, Oxford, UK, 2016.

[19] W. L. Fourney, D. C. Holloway, and J. W. Dally, "Fracture initiation and propagation from a center of dilatation," International Journal of Fracture, vol. 11, no. 6, pp. 1011-1029, 1975. 